Volume 6, Issue 4, 441 - 453.

ISSN: $2165-8714$

http://www.eu-jer.com/

\title{
Effect of Feedback Strategy and Motivation of Achievement to Improving Learning Results Concept in Learning Civic Education in Vocational High School
}

\author{
Sumarno * \\ Vocational High School 5, INDONESIA
}

\author{
Punaji Setyosari \\ Universitas Negeri Malang, INDONESIA
}

Haryono
Universitas Negeri Malang, INDONESIA

Received: September 14, $2017 \cdot$ Revised: October 8, $2017 \cdot$ Accepted: October 10, 2017

\begin{abstract}
This study aims to examine the effect of feedback strategies on understanding and applying the concept of National ideology to students who have different achievement motivation, on learning Citizenship Education in vocational high schools. This research uses quasi experiment research design (Quasi Experiment). The subjects of this study were 133 vocational high school students. The research instrument used the achievement motivation questionnaires and test appraisal tools of understanding and application of the concept. Research data were analyzed using MANOVA (Multivariate Analysis of Variance) method with 2x2factorial. The results reveal three findings, namely: (1) there are differences in posttest score of understanding and application of concepts between groups of direct and indirect feedback strategies; (2) there is difference of posttest score of understanding and application of concept between high and low achievement motivation group: (3) interaction between feedback strategy with achievement motivation does not influence simultaneously to understanding and application of concept.
\end{abstract}

Keywords: Feedback strategies, achievement motivation, understanding and application of concept

To cite this article: Sumarno, Setyosari, P., \& Haryono (2017). Effect of feedback strategy and motivation of achievement to improving learning results concept in learning civic education in vocational high school. European Journal of Educational Research, 6(4), 441-453. doi: 10.12973/eu-jer.6.4.441

\section{Introduction}

The common problem of National ideology and Citizenship education in Vocational High School is that instructional activities of National ideology values gives more emphasis on aspect of general understanding and less emphasis on understanding and applying substance of concept. Learning outcomes in the form of conceptual understanding is always not in line with the results of learning ability to use or application of the concept. Students are able to understand and memorize the definition of concepts related to the values of National ideology such as the value of divinity, humanity, unity, democracy and justice, but they are not able to apply the concept to analyze various phenomena of cases that occur in society. As an illustration, students understand and memorize the definition of the concept of "justice" values but are unable to assess "just" and "unequal" conditions in society. It is shown by the daily test, midterms and final semester test obtained by the students which are still below the criteria of learning completion standard set by the school. The learning outcomes show negative impact; that National ideology learning does not succeed in realizing the ideals of National ideology in schools. The learning goals of National ideology in schools aims at building up students who are able to: (1) have characters that reflect the comprehension, understanding, and practice of National ideology values personally and socially; (2) have a constitutional commitment supported by a positive attitude and a complete understanding of the constitution of the 1945 Constitution of the State of the Republic of Indonesia; (3) think critically, rationally, and creatively and have the spirit of nationalism and love of the homeland that is imbued by the values of Pancasila, the 1945 Constitution of the Republic of Indonesia, the spirit of Bhinneka Tunggal Ika, and the commitment of the Unitary State of the Republic of Indonesia, and 4 ) participate actively, intelligently and responsibly as members of the community, nation, and citizens according to their position as creatures of God Almighty living together in various socio-cultural order.

Learning National ideology in schools is considered unsuccessful in realizing the goals, which is caused by three factors, namely: (1) indoctrinative-normative learning, (2) lack of activity of students developing critical thinking ability, positive, constructive and productive thinking, and (3) learning less awakening awareness of value- the noble value that guides the student towards the morality of human beings (Adimasa, 2000:32). How to design the learning of National ideology effectively and efficiently and attract students to learn the ideology of Pancasila? Learning the

\footnotetext{
* Corresponding author:

Sumarno, Vocational High School 5, Malang, East Java,Indonesia,

E-mail: sumarno@smkn5malang.sch.id
} 
ideological values of National ideologythat is not indoktrinative, based on student activities and develop critical thinking skills and foster awareness of noble moral values.

Effective learning is learning that focuses on the importance of learning as a personal process, in which each student builds his personal knowledge and experience (Marzano, 1992; Callahan, Clark, \& Kellough, 1995). Personal knowledge and experience are built by students through interaction with the environment. This opinion is reinforced by Brooks \& Brooks (1993) which states that basically students themselves construct meaning about what they learn. Effective learning is determined by several factors including material mastery, participation in teaching and learning, strategies designed specifically for presenting materials, and student responses to strategies used in teaching. Effective learning according to Marzano (2004) comprises nine learning strategies, namely: (1) identifying similarities and differences; (2) summarize and record; (3) strengthening business and providing recognition; (4) homework and practice; (5) represents knowledge (nonlinguistic representation); (6) study groups; (7) set goals and provide feedback; (8) generate and test the hypothesis; (9). gestures, questions, and face-to-face. Marzano's opinion is in line with the opinion of Gagne (1985), that effective learning consists of nine main stages of activity, which include: (1) attracting attention; (2) notify the learning objectives to the students; (3) stimulate memory on the prerequisites of learning; (4) presenting stimulants, (5) providing study guidance; (6) encouraging for-work; (7) provide informative feedback; (8) assess performance, and (9) improve retention and transfer of learning. Based on the two effective learning concepts from Gagne and Marzano mentioned above, it is concluded that an activity that attracted the author's attention is the activity of giving feedback. Do teacher feedback or feedback activities to students improve learning outcomes? Teacher feedback as information communicated to students whether can be a means of modifying the thinking or behavior of students in order to make improvements in the quality of learning outcomes?

Teacher's feedback activity to students in general based on research results is considered as a strategic activity to improve the knowledge and acquisition of learning ability. Teachers are not only influential in achievement, but are also considered as important factors to motivate students in learning (Shute, Valerie. J, 2008: 2). However, research on the relationship of feedback with the learning process and the performance outcomes of students published during the last fifty years (Bangert-Drownds, 1991, Kluger \& De Nisi, 1996; Kulhavy \& Stock, 1989; Kulhavy \& Wager, 1993) show conflicting findings and there is no consistent pattern of results. The researchers conducted a meta-analysis using descriptors such as "inconsistent", "contradictory" and "very varied" terms to describe the number of research findings (Azevedo \& Bernard, 1995; Kluger \& De Nisi, 1996). The researchers recommend to deeply understand the contribution of feedback in learning so it is necessary to further study the effect of feedback on high learning outcomes and be attributed to the characteristics of students (Shute, 2008,153).

Effective learning is also determined by the characteristics of students. Characteristic of students or aspects of personal quality related to learning conditions is a factor of achievement motivation that is owned by students. Achievement motivation by Mc. Clelland (1987: 40) is defined as an attempt to achieve success or success in a competition with a measure of excellence that can be either the achievements of others or their own achievements. Lindgren (1976: 67) argues that achievement motivation as an impetus exist in a person with respect to achievement, which is mastering, manipulating and regulating the social and physical environment, overcoming all obstacles and maintaining high quality work, competing through efforts to beyond the past work, and outperformed the work of others. Factors of achievement motivation influential in the selection of strategies and learning outcomes.

Based on the problem of National ideology learning in schools as described, researchers conducted a study on the use of feedback strategies which is associated to achievement motivation of students in learning National ideology using inquiry jurisprudence model and its effect on understanding and application of the concept. Do the feedback strategies used by the teacher and the difference in achievement motivation of the students influence the learning outcomes of understanding and application of the concept? To find answers to these questions, it is necessary to collect data through research involving research subjects of vocational high school students.

\section{Literature Review}

\section{Learning Feedback Strategy}

Feedback in this study is the information communicated to students and aimed at modifying the thinking or behavior of students in order to improve the quality of learning outcomes. Feedback in Webster's Dictionary (2001:520) defined as a process by which factors that create results can be modified, corrected, reinforced and so on with the result and a response, which drives a process. The types of feedback that will be studied in this research are direct or immediate feedback and indirect or delayed feedback strategies (Shute, Valerie.J. 2008: 154).

The results of teacher feedback research in learning are generally regarded as a strategic element for improving knowledge and ability acquisitionl. It is shown by research conducted by Azevedo, \& Bernard, 1995; Bangert-Drowns, Coolies, Kulik, \& Morgan, 1991; Moreno, 2004; Pridemore \& Klein, 1995 (Shute, 2008: 153). In addition to impact on achievement, teacher feedback is also considered an important factor to motivate learning, according to research: Lepper \& Chabay, 1985; Narciss, \& Huth, 2004 (Shute,2008:153). Cohen (1985) suggests that teacher feedback is one of the most significant aspects of learning design. 
Direct or immediate feedback is defined as feedback that is immediately given after the students respond or complete the task. While indirect or delayed strategy feedback is defined as opposed to direct, feedback given several hours, several weeks or so long after the completion of a task or repetition. Differences in the use of immediate and delayed feedback are thought to influence learning outcomes. The influence of time variables when feedback is given is not known for certain, but there is an interaction between the time of feedback and learning feedback. Some researchers support direct feedback as a means of preventing errors from being embedded in students' memory, while other researchers suggest that delayed feedback can reduce proactive interference, allowing errors to be forgotten and correct information can be stored without interruption (Kullhavy \& Anderrson, 1972).

Supporters of direct strategy feedback suggest the theory that the more rapidly the corrective information is given, the greater the likelihood that it will produce an efficient retention (Phye \& Andre, 1989). Excess direct strategy feedback compared to indirect or delayed feedback is known from the acquisition of informational materials, procedural skills, and some motor skills (Anderson, Magill, \& Sekiya, 2001; Brosvic and Cohen, 1988; Corbett and Anderson, 1989; Dihoff, Brosvic, Epstein, \& Cook, 2003). Proponents of the use of delayed feedback generally refer to the interferenceperseverence hypothesis proposed by Kulhavy and Anderson (1972). This confirms that the initial error is not related to the correct answer to be learned if the corrective information is delayed and the error will be easily forgotten. Schrocth (1992) presents the results of an experiment that examines the effects of delayed feedback and the type of verbal feedback on transfer using a concept-forming task. Initial conclusions from the findings of Schrocth's (1992), Corbet and Anderson (2001) researches are that delayed feedback may be more effective for improving learning transfers, especially in relation to the task of concept formation, whereas direct feedback is more efficient especially for the short term and for procedural skills. The proposition also gained support, for example (Schmidt, 1989) conducted an experiment that provided verification feedback after a set of experiments on simple ballistic timing tasks. Experimental results that longer delay times between one feedback and another create worse performance during the acquisition phase but create better retention when compared to conditions with shorter delays.

Kulhavy and Stock (1989) report that learning feedback can be in the form of verification and elaboration. The feedback in the form of verification is a simple assessment of whether an answer is correct or not, and the elaborate feedback is in the form of relevant instructions to guide students to get the correct answer. The researchers agree with the view that effective feedback should include elements of verification and elaboration (Bangert-Drowns, 1991, Mason and Bruning, 2001). The verification-shaped feedback or correction verification can be communicated in several ways to confirm whether an answer is right or wrong. The most common way is simply to state "true" or "false". Besides that, explicit verification can be given by thickening or assigning an answer to indicate the truth (eg with check marks) or providing certain information to the student. The elaborate feedback has more variation than the verification feedback for instance, (a) describing a topic, (b) describing a response, (c) discussing a particular error, (d) giving an example already done, or (e) providing a guide. The researchers agree that one type of elaboration, feedback specific to a particular response can improve student achievement, especially learning efficiency, and that is better than other types of feedback such as simple verification or "answer to right" (Corbett \& Anderson, 2001; Gilman, 1969; Mory, 2004; Shute, Hansen, \& Almond, 2007). The specificity of the feedback proved to affect performance when interacting with the student's target orientation.

Feedback delivery procedure can be done using several models, namely: certitude model, five-stage mindfulness model, constructive model and self regulation model (Mory, 2010: 745). This study uses the model of "Five-Stage Mindfullness Model" with the consideration of this model is constructive, relevant to the characteristics of students who became the center of research attention. The five stages are: (1) the initial stages of the student, (2) the search and withdrawal strategies used, (3) the response of the student's task, (4) the evaluation of the answer, and (5) the decision on the adjustment made by the student. This model emphasizes meaningful constructs (Salomon \& Globerson, 1987), and is called a reflective process in which students attempt to extract situational clues and meanings related to the task performed (Dempsey, Driscoll, \& Swindel, 1993, p. 38). This model describes the behavioral and cognitive operations that occur in the learning process. This model directs students' behavior to be able to monitor the physical changes created. Students change their cognitive operations and activities as they adjust to new information and match it to their expectations of a performance (Bangert-Drowns,1991). This modeling procedure emphasizes the meaning construct, in which the activity performed is not an automated response that has been previously learned. Feedback can improve the quality of learning if the feedback is digested meaningfully. Human being can also inhibit the learning process if feedback raises fears, such as when feedback is given before learning does a search in their memory or if the learning given is too easy. Therefore feedback should be constructive and given in the relevant context (Brown et al., 1989, Jonassen, 1991) or known as the name of situated cognition, meaning that learning will be effective in certain contexts and the context becomes the main part of actual knowledge in the learning (Jonassen, 1991). One such approach is called cognitive guidance, where students engage in activities and take advantage of existing physical and social contexts (Brown, 1989; Collins, Brown, \& Newman, 1987). According to this view, feedback occurs in the form of interaction between students and real problem-solving activities. Feedback can also be used as a coaching mechanism that analyzes strategies for solving such problems (Jonassen, 1991). When a student views the problem from a particular point of view, teacher feedback can serve to guide the student to re-discuss the same material in a 
rearranged context, for different purposes and with different conceptual perspectives (Spiro, 1991) or a combination both. In general feedback is used to allow students to evaluate goals through strengthening the installation of answers or through learning controls. But according to the constructivist view, the evaluation provided by feedback will be a means for self-analysis (Jonassen, 1991).

The main purpose of feedback is to improve students' knowledge, skills and understanding of particular general or field skills, such as problem solving, and various types of feedback can be used for other purposes. For instance, feedback is employed to perform a particular task improvement and is immediately given. Black and William (1998), suggest there are two main functions of feedback: the directive and facilitative functions. The feedback directive is a feedback that tells the student what to fix or revise. The directive type of feedback tends to be more specific when compared with facilitative feedback, which provides comments and suggestions to assist students when making revisions and conceptualizations.

The constructive effects of feedback (Mory, 1995) in the learning process are: (1) helping students construct internal reality by providing intellectual means, (2) helping students solve problems in contextual settings; (3) guide the representation model, (5) guide students through unstructured domains, and remind students of their goals and (6) challenge students to grow.

\section{Achievement Motivation}

Achievement motivation is defined as an attempt to achieve success or success in a competition with a measure of excellence that can be either the achievements of others or their own achievements (McClelland,1987: 40). Lindgren (1976: 67) argues that achievement motivation as an impetus to a person in terms of achievement, that is mastering, manipulating the fibers organize the social and physical environment, overcoming all obstacles and maintaining high quality work, competing through efforts to beyond the past work, and outperformed the work of others.

Achievement motivation is the desire to accomplish something to achieve a standard of success, and to make a business with the aim to achieve success (Santrok, 2003: 103). Gagne and Barliner (1975: 77) add that achievement motivation is one's attempt to do well for his achievement. Heckhausen (1967: 54) describes achievement motivation as an attempt to improve or conduct the highest possible personal skills in all activities and a measure of excellence is used as a benchmark, although in the effort to engage in these activities there are two possibilities of failure or success. Achievement motivation is the motive that encourages individuals to achieve success and aims to succeed in competition with some measure of excellence (standard of excellence). The measure of excellence is used for the standard of achievement excellence achieved itself before and feasible as in a competition. Based on expectancy-value theory, Atkinson (1960: 56) suggests that the motivation of achievement is based on two things, namely the tendency to achieve success and the tendency to avoid failure. Basically the state of motive is owned by the individual, but both have different circumstances in various situations and conditions according to the achievement. Atkinson (1958: 34) argues that individual success to achieve success and win the competition based on the standard of excellence is closely related to the personality type who has a higher achievement motive than the motive to avoid failure and vice versa, if the motive to avoid failure is higher than the motive of success, then one's achievement motivation tends to be low. From the description it can be concluded that achievement motivation is an impulse related to how to do something better, faster, more efficiently than what has been done before, in an effort to achieve success or succeed in competition with a measure of excellence that can be in the form of achievement others as well as their own achievements.

There are characteristics of individuals who have high achievement motivation, namely: 1) a strong feeling to achieve goals, namely the desire to complete the task with the best results. 2) being responsible, that is ability to take responsibility for himself and determine the future in order to achieve the goal. 3) being evaluative, using feedback to determine more effective actions to achieve achievement, failure experienced did not make him despair, but as a lesson to succeed. 4) Taking a "moderate" risk, in the sense that its actions correspond to the limits of its capability. 5) being creative and innovative, that is able to find opportunities and use the opportunity to be able to demonstrate its potential. Individuals with low achievement motivation have characteristics that are contrary to the characteristics of highly motivated individuals as described above (David Mc Clelland ,1978: 77)

\section{Understanding and Implementation of Concepts}

The cognitive learning outcomes of understanding on Bloom's taxonomy are at the second level. Understanding is the ability to construct the meanings of learning messages, whether they are oral, written or graphically conveyed through teaching, books, or computer screens (Anderson, \& Krathwohl, 2001: 105).

Taxonomy of understanding ability includes the following abilities: interpreting, modeling, classifying, summarizing, summarizing, comparing and explaining. Interpretability occurs when students change information from one form to another, such as from a word to a picture or vice versa. The ability to model is the ability to identify the essential features of a general concept or principle and use these characteristics to create other examples. The ability to classify is a cognitive process that complements the process of modeling. If exemplification starts from a general concept or principle then finds an example, classifies starting with a particular instance by requiring to find a general concept or 
principle. The ability to summarize is the ability to express a sentence that presents information received or abstracted a theme. Ability to conclude occurs when students can abstract a concept or principle with examples by looking at the characteristics of each instance and drawing connections between the characteristics of the sample. The ability to compare is the ability to detect the similarities and differences between two objects, events, ideas, problems, or situations that occur. Ability to explain is the ability to use causal models in a system and model derived from the theory, results of research, or the experience of students.

The conceptual model of understanding invented by Bruner (Degeng, 2013: 115) is repeatedly used terms, such as: examples, criteria, and attributes or characteristics to describe categorizing and conceptualizing activities. Bruner (1980) considers that a concept has five elements and one is said to understand a concept when it knows all the elements of that concept. These five elements are: names, positive and negative examples, principal characteristics or not, characteristic range, and rules. Gagne in Degeng (2013: 93) states that conceptual understanding as an intellectual skill is categorized into two types: concrete and abstract concepts. Students learn concrete concepts when they can identify new or untested examples from a group of objects or groups of objects. The concrete concept identified pointing to, or marking on, instances, and usually can not be identified by definition. Abstract concept, it is said to learn abstract concept when students use definition to clarify examples that have not been studied before.

Bruner developed different strategies to achieve different types of concepts. There are three strategies for organizing conceptual learning that have been developed, namely: (1) acceptance model, (2) choice model, and (3) model of unorganized example. The acceptance model refers to the strategy of organizing concept examples by giving a "yes" mark, if the example is an example of a concept, and a "no" if the example is not an example of a concept. The choice model refers to the strategy of organizing concept examples without giving a "yes" or "no" sign. A model with an unorganized example refers to a concept understanding strategy by using unorganized examples in the real life environment.

Cognitive "implementation" or "application" cognitive learning outcomes are the result of the ability to use certain procedures to solve problems or practice problems (Anderson \& Krathwohl, 2001: 116). The exercise problem is the task that the completion procedure is known to students. The problem is the task that the completion procedure is not yet known to students. The learning outcomes of applying or applying categories consist of two cognitive processes, which execute and implement. Category executes if the task is just a matter of exercise and category implements if the task is a problem solving.

The concept, according to Dick and Carey (2004) is an object, a symbol, a situation that can be grouped with each other based on one or more characteristics and is usually identified by name or symbol. Concepts based on their form are classified into two types (Gagne, 1989), namely: concepts based on observation and by definition. The concept is an abstraction of concrete experience results. Abstraction is done by taking the characteristics of the object of concern and discarding irrelevant features. Concepts learned from perceptions of objects are reinforced by prior experience. Concepts by definition are concepts in the form of verbal formulas using words or sentences.

Understanding the concepts in learning the ideology of National ideologyand citizenship (civics) are tangible abilities, namely: interpret, exemplify, classify, summarize, summarize, compare and explain the meaning of the value of learning messages, both oral, written, graphical objects, symbols, and situations. The possible ways to understand concepts are to make definitions with language structures that are easily understood by students, giving examples relevant to concepts, or comparing with other concepts that can be identified by their similarities and differences.

Application of the concept as a process of transformation of conceptual knowledge is a representation of learning outcomes. Students apply the concept if students are able to use procedural knowledge to solve various problems related to concepts learned in civics learning, for example the concept of values of justice, responsibility, tolerance, tolerance, humanity and other moral values.

\section{Interaction of Feedback, Student Motivation and Learning}

The relationship between feedback variables, achievement motivation and learning outcomes can be explained from various theories about learning. From the point of view of the behaviorist theory, learning is defined as a conditioning where behavior followed by reinforcement will increase in frequency or probability (Operant conditioning from Skinner). Teacher feedback to students is seen as reinforcement, with the aim of helping students progress from mastering simple task completion procedures to complex tasks. The rationale of the behaviorist can be seen clearly, that is the feedback coming from external sources to be able to adjust the external learning outcomes with the students performance for certain tasks. The general view of feedback is considered as a motivator or incentive to improve response and / or accuracy (Kulhavy \& Wager, 1993).

The view that feedback serves as a motivator or incentive for learning still prevails in classes today, but there is confusion to distinguish between praise and feedback related to learning content (Hattie \& Timperley, 2007). Deci, Koester, and Ryan (1999) found that when teachers reward concrete as a feedback, intrinsic motivation is significantly reduced and students are reluctant to motivate or self-organize. Feedback as extrinsic rewards often encourages 
students to put more emphasis on incentives, leading to higher competition intensity rather than high involvement in learning.

Narciss and Huth (2004) explain that effective feedback is that which is designed by linking to other important variables in the learning process i.e the "students" and "learning" variables. The learning or context variable consists of three main elements: (a) learning objectives (learning goals or standards related to the curriculum); (b) learning tasks (knowledge items, cognitive operations, metacognitive skills) and (c) (such as the usual stealth, the wrong strategy, the source of the error). Student variables include information about students relevant to the feedback design including (a) learning objectives and objectives, (b) prior knowledge, skills and abilities (which depend on domains, such as knowledge of subject matter, and depending on the domain, such as metacognitive skills) and (c) academic motivation (one's need for academic achievement, academic self-talk, and meta-motivational skills). While the feedback variable consists of three main elements: (a) the feedback content (evaluative aspects, such as verification, and informative aspects, clues, analogs, explanations and examples already described), (b) feedback function (cognitive, metacognitive, and motivational) and (c) presentation of the feedback components (timings, schedules and possibly considerations of adaptability).

\section{Methodology}

\section{Research Goal}

The purpose of the study was to examine and to know the following: (1) Differences in posttest scores of understanding and application of concepts between groups of students who were given direct methods with groups that were given an indirect method of studying the ideology of the state. (2) Differences in postes score of concept comprehension on groups of students with high achieving motivation with low achievement motivation group on Civics learning with inquiry strategy of jurisprudence. (3) Interaction between reversal methods and achievement motivation on understanding and application of concepts on the learning of state ideology.

\section{Sample and Data Collection}

The subjects of this study were students of SMK in SMK Negeri 5 Malang, East Java, Indonesia. The subjects of this study are the students of class X of 680 children who are divided into 22 study groups or classes and time limitation factors and the availability of tuition fees. Sample of research of secra random taken four class. The research instrument used the achievement motivation questionnaires and test appraisal tools of understanding and application of the concept.

\section{Analyzing of Data}

Research data were analyzed using MANOVA (Multivariate Analysis of Variance) method with 2x2 factorial

\section{Findings / Results}

After conducting normality and homogeneity test, the conditions are met, then proceed with the test of difference test. Difference test is done by administering different test to mean score comprehension and application of concept. Based on the results of the acquisition value of the average score of understanding and application of the concept, it can be known statistically whether the difference in the score difference of each variable is meaningful. The results of the average difference test obtained are as follow

Table 1. Test Results Difference Score Understanding and Implementation Concepts Group of Direct and Indirect Feedback Strategies

\begin{tabular}{|c|c|c|c|c|}
\hline Outcomes Learning & Feedback strategies & Average & t- hit & Sig \\
\hline \multirow{2}{*}{ Consepts Understanding } & Indirect/Delayed & 65.5577 & \multirow{2}{*}{0.445} & \multirow{2}{*}{0.657} \\
\hline & Direct/Immediate & 64.8000 & & \\
\hline \multirow{2}{*}{ Consepts Aplication } & Indirect/Delayed & 51.1923 & \multirow{2}{*}{-4.101} & \multirow{2}{*}{0.000} \\
\hline & Direct/ Immediate & 67.2000 & & \\
\hline
\end{tabular}

Based on table 1, it can be seen that the average score of understanding of group concept of indirect feedback strategy is 65.5577 while the direct feedback strategy is 64.8000 . The average difference between the scores of both feedback strategies is 0.7577 . The magnitude of the mean difference is not considered statistically significant (sig $=0.657$ ) because the mean score of concept comprehension on the student group of direct and indirect feedback strategies does not differ greatly.

While for score of concept application, the average in group of direct feedback strategy is equal to 67.2000 and indirect strategy equal to 51.1923. The difference of the scores on both strategies is 16.0077 . The average difference in concept applying scores is very different in magnitude compared to concept scores. This is evident from the statistical results 
stating that there is a significant difference $(\mathrm{sig}=0.000)$ on the score of application of concepts between students groups of direct and indirect feedback strategies.

Then tested whether there are differences in understanding scores and application of concepts in groups of students who have high achievement motivation and low.

Table 2. Test Results Difference Score Understanding and Implementation Concepts Low Achievement Motivation Group and High

\begin{tabular}{|c|c|c|c|c|}
\hline Outcomes Learning & Achievement Motivation & Average & t-hit & Sig \\
\hline Concepts Understanding & $\begin{array}{l}\text { Low } \\
\text { High }\end{array}$ & $\begin{array}{l}64.8261 \\
65.4821\end{array}$ & -0.384 & 0.702 \\
\hline Concepts Implementation & $\begin{array}{l}\text { Low } \\
\text { High }\end{array}$ & $\begin{array}{l}52.1087 \\
64.7321\end{array}$ & -3.120 & 0.002 \\
\hline
\end{tabular}

Based on table 2, the average score of concept comprehension on low and high achieving motivation group is 64.8261 and 65.4821. The average difference between low and high achieving motivation scores was 0.656. Statistically, the magnitude of the average difference is considered meaningless (sig $=0.702$ ) because the two averages do not differ much. There is no difference in the mean score of concept comprehension between low motivation group students with low achievement motivation group.

While on concept applying score, got the average in low achievement motivation group equal to 52.1087 and high achievement motivation equal to 64.7321. The difference of the scores on both strategies is 12.6234. The average difference in these scores is very different compared to the concept draft score. The value of significance obtained $=$ 0.002 which reinforces the result that the magnitude of the difference in score is very real. So on the score of application of the concept between low and high achievement motivation group there is a significant difference.

Overall, the different test results on the score of understanding and application of the concept based on the independent variables of feedback strategy and achievement motivation showed that the feedback strategy and achievement motivation were not significantly different from the concept concept score but significantly different to the score of concept application. In this research, we want to know more about whether there is interaction between feedback strategy and achievement motivation on understanding score and concept application. Since it involves two variables simultaneously it will first test multivariate effects using the F test sourced from Wilks' Lambda, Hotelling's Trace, Roy's Largest Root and Pillai's Trace. The results obtained are as follows

Table 3.Test Result F Interaction Feedback Strategy, Achievement Motivation On Score of Understanding and Implementation of Concepts

\begin{tabular}{|c|c|c|c|}
\hline & $\begin{array}{l}\text { Feedback } \\
\text { Strategies } \\
\end{array}$ & $\begin{array}{c}\text { Achievement } \\
\text { Motivation }\end{array}$ & Interaction \\
\hline Wilks' Lambda & 0.010 & 0.001 & 0.804 \\
\hline Hotelling's Trace & 0.010 & 0.001 & 0.804 \\
\hline Roy's Largest Root & 0.010 & 0.001 & 0.804 \\
\hline Pillai's Trace & 0.010 & 0.001 & 0.804 \\
\hline
\end{tabular}

Based on table 3 of multivariate test results, the results obtained that the feedback strategy and achievement motivation have a significant influence simultaneously on the variable score of understanding and application of the concept. But not on the interaction of both. To know more can be seen from the following table:

Tests of Between-Subjects Effects

\begin{tabular}{|c|c|c|c|c|c|}
\hline & $\begin{array}{l}\text { Dependent } \\
\text { Variable }\end{array}$ & $\begin{array}{l}\text { Type III Sum df } \\
\text { of Squares }\end{array}$ & $\begin{array}{l}\text { Mean } \\
\text { Square }\end{array}$ & \multicolumn{2}{|c|}{ Sig. } \\
\hline \multirow{2}{*}{ Achievement Motivation } & $\begin{array}{l}\text { Understanding } \\
\text { Concepts }\end{array}$ & 13.4321 & 13.432 & 0.179 & 0.673 \\
\hline & $\begin{array}{l}\text { Implementation } \\
\text { Concepts }\end{array}$ & 3467.6551 & 3467.655 & 9.626 & 0.003 \\
\hline & Understanding Concepts & 19.5861 & 19.586 & 0.261 & 0.610 \\
\hline Feedback Strategies & $\begin{array}{l}\text { Implementation } \\
\text { Concepts }\end{array}$ & 5735.2051 & 5735.205 & 15.921 & 0.000 \\
\hline $\begin{array}{l}\text { Achievement Motivation * } \\
\text { Feedback Strategies }\end{array}$ & $\begin{array}{l}\text { Understanding } \\
\text { Concepts }\end{array}$ & 16.5931 & 16.593 & 0.221 & 0.639 \\
\hline
\end{tabular}


Implementation

Concepts

90.7091

90.709

0.252

0.617

MANOVA test results in testing the presence or absence of interaction between feedback strategies and achievement motivation showed that the sig obtained in the concept comprehension score of 0.639 and the score of application of the concept of 0.617 . Both variables have sig value> 0.05 so it is concluded that there is no meaningful interaction between feedback strategy and motivation. The feedback and motivation strategy, each having partial effect only on concept implementation scores only ( $\mathrm{sig}<0.05)$. This is in line with previous average difference test results.

\section{Discussion and Conclusion}

\section{Effect of Feedback Strategies on Understanding and Application of Concepts}

Based on the results of the number one hypothesis test, there are significant difference of concept understanding and significant difference of concept application of the two who received direct or immediate feedback strategy treatment with indirect or delayed feedback strategy group. The result of different test statistic shows that the mean score of the learning achievement result of the concept of the group of students receiving direct feedback strategy is 64.8000 while the group receiving the indirect or delayed feedback strategy is 65.5577 . The average difference between the scores of both feedback strategies is 0.7577 . The magnitude of the mean difference is not statistically significant (sig $=0.657$ ) because the mean score of conceptual learning achievement outcomes in the group of students who were treated with direct and delayed feedback strategies did not differ greatly.

While the score of learning outcomes of the application of the concept, obtained on average in the group of students who were given immediate or direct feedback strategy of 67.2000 and group of indirect or delayed feedback strategy amounted to 51.1923. The difference in the scores of both feedback strategies is 16.0077. The average difference in the scores of learning outcomes for the application of concepts is very different in magnitude when compared with the results of learning scores concept. This is evident from the statistical results that there is a significant difference (sig $=$ 0.000) on the score of learning outcomes of the application of concepts between the groups of students who were treated with direct feedback strategies with the groups who were given feedback strategies are not directly or delayed The conclusions of the research findings are that there is a difference in learning outcomes of understanding and application of concepts between groups of students who received immediate or direct feedback strategy treatment with indirect or delayed feedback strategy groups. With other statements, the use of immediate or immediate and indirect or delayed strategy feedbacks can improve understanding of concepts and application of concepts in the form of skills using problem-solving procedures. The effect of feedback strategy is significant is on the results of concept application.

Factors suspected to be the cause of the differences are the feedback strategies used by teachers. There are several cognitive mechanisms that students use to use feedback from teachers in learning. First, feedback can indicate the level of recent performance and performance levels or objectives expected. Feedback can mask the gap and motivate students to do more effort (Locke and Latham, 1990; Song and Keller, 2001). Feedback can reduce uncertainty about the success or failure of students performing a task (Ashford, 1986; Ashford, Blatt and Vande Walle, 2003). Uncertainty is a negative condition that encourages the emergence of a strategy to reduce or manage the condition (Bordia, Hobman, Jones and Calan, 2004). Because uncertainty is often unpleasant and diverts attention from task performance (Kanfer and Ackerman, 1989), uncertainty reduction can increase motivation and lead to more efficient task strategies. Second, feedback can reduce the cognitive load of students, especially students at the graduate level or students with problems (Paas, Renkl, and Sweller, 2003; Sweller, Van Merrienboer and Paas, 1998). Students may be cognitively exhausted during learning because of high performance demands and they benefit from supportive feedback designed to lower cognitive loads. In fact, Sweller and colleagues (1998) provide support by showing how the presentation of workable examples can reduce the cognitive burden on low-ability students who face difficult problem-solving tasks. Moreno (2004) provides additional support by using explanatory feedback to assist students at the graduate level.

Third, feedback can provide useful information for correcting inappropriate task strategies, procedural errors or misconceptions (eg Ilgen, et al, 1979, Mason and Bruning, 2001; Mory, 2004; Narciss and Huth, 2004). The effect of such corrective function seems strong enough for more specific feedback (Baron, 1988; Goldstein, Emanuel and Howell, 1968).

The findings of this study are in line with the results of the study: Azevedo, and Bernard, 1995; Bangert-Drowns, Coolies, Kulik, Morgan, 1991; Moreno, 2004; Pridemore and Klein, 1995 (Shute V, J. 2008. 153) they conclude that in general the task feedback or evaluation results are considered to be important in improving the knowledge and acquisition of students' abilities. In addition to its impact on achievement, feedback is also considered an important factor to motivate learning, in line with the conclusions of the research results: Lepper and Chabay, 1985; Narciss, and Huth, 2004 (Shute V, J. 2008. 153). 
Analysis of the influence of feedback in learning depends on the learning theory used in learning, namely: behavioral, cognitive, constructive or self-regulation. Feedback in the perspective of behavioral theory is seen as reinforcement, with the aim of helping students in the completion of simple tasks to complex tasks (Marieke, T. 2013: 3). Giving feedback or feedback in the perspective of cognitive theory explains that feedback or feedback serves not only to reinforce correct answers but also to be corrective information to help students to correct or verify their mistakes (Marieke, T. 2013: 4). Giving feedback in the perspective of constructive theory, feedback or feedback is a form of interaction between students and learning activities of real problem solving and as a means of constructive process. Students use feedback to shape, elaborate, and test the mental structure until a satisfactory mental structure is obtained, and it will continue to change as the students' experience clashed with new information that eventually triggered a new restructuring (Marieke, T. 2013: 4). Feedback or feedback in the perspective of self regulation theory emphasizes the importance of the interaction between feedback and recipient information and emphasizes the active involvement of students to seek clues and monitor and evaluate their own performance (Marieke T, 2013: 4).

The findings of this study confirm that teacher feedback in the learning process has a constructive effect (Mory, 1995), as follows: (1) helping students construct internal reality by providing intellectual means, (2) helping students solve problems in contextual settings; (3) guide the representation model, (5) guide students through unstructured domains, and remind students of their goals and (6) challenge students to grow.

\section{The Influence of Achievement Motivation on Understanding and Application of Concepts}

Based on the result of hypothesis test number two, that is there is significant difference of concept understanding, and concept application between groups with high achievement motivated with low achievement motivated group. The average difference in the learning outcomes of understanding did not differ greatly between the two treatment groups, whereas significant differences were found in the learning outcomes of concept application.

The results of different test statistics have shown that the average score of the learning achievement of conceptual understanding in the group of students with low achievement motivation is 64.8261 and the group of high achieving motivated students is 65.4821 . The difference in the average score of the two low achieving motivation groups is 0.656 . Statistically, the magnitude of the average difference is considered meaningless $(\mathrm{sig}=0.702)$ because the two averages do not differ much.

While the score of learning outcomes of the application of the concept, obtained on average in the group of students who have low achievement motivation of 52.1087 and group of students with high achievement motivation of 64.7321 . The difference in the average score of both achievement motivation is 12.6234. The average difference in scores is also very different compared to the conceptual learning outcome scores. The value of significance obtained $=0.002$ which reinforces the result that the magnitude of the difference in score is very real.

The conclusion of the research findings is that the learning result of concept comprehension between low and high achievement motivation group is not found very real difference, the difference of the mean difference of high motivated group score with low is very small that is 0656 and is not statistically significant. The real difference between low motivated and high group is found in the learning result of the application of concept with the average score that is 12.6234. Thus the achievement motivation factor is very instrumental in the results of learning application of the concept.

This finding is in line with the results of Dimyati (2012) study on the influence of achievement motivation on learning outcomes and student attitudes with findings, that there are differences in learning outcomes and attitudes between high-motivated student groups and low-motivated student groups. Similarly, in line with the results of Sunariyah (2016) research on the influence of achievement motivation on learning outcomes and scientific attitudes with the findings, that there are differences in learning outcomes and scientific attitudes between groups of highly motivated students with low-motivated achievers. Based on findings of this study and previous ones, student achievement motivation as characteristic of student (Degeng, 2013: 67) is proven to be an influential factor in the acquisition of student learning outcomes.

In expectancy-value theory Atkinson (1960: 56) suggests that the motivation of achievement is based on two things, namely the tendency to achieve success and the tendency to avoid failure. Basically the state of motive is owned by the individual, but both have different circumstances in various situations and conditions according to the achievement. Atkinson (1958: 34) argues that individual success to achieve success and win the competition based on the standard of excellence is closely related to the personality type who has a higher achievement motive than the motive to avoid failure and vice versa, if the motive to avoid failure is higher than the motive of succes, then one's achievement motivation tends to be low. 
The group of students with high motivation to gain better understanding and application of concepts, according to Heckhausen (1987) and Keller (in Degeng, 1991) that high motivated students will always work hard, tough, not easily despair, wanting to get higher achievements, worry about failure, future-oriented, enjoying difficult tasks, liking quick feedback about her achievements, also responsible for solving problems.

The interaction of feedback strategies and achievement motivation and their impact on understanding and application of concepts.

Interaction is the cooperation of two or more independent variables in influencing a dependent variable (Kerlinger, 1986). The effect of interaction is the joint effect of two or more independent variables on the dependent variable. Based on the multivariate test results table, the results obtained that the feedback strategy and achievement motivation have a significant influence simultaneously on the variables of understanding and application of concepts. But not on the interaction of both. Manova test results in testing whether or not the interaction between the feedback strategy and achievement motivation showed that the number of significance obtained on the score of learning outcomes concept understanding of 0.639 and the score of learning outcomes of application of the concept of 0.617 . Both variables have sig value $>0.05$ so it is concluded that there is no meaningful interaction between feedback strategy and achievement motivation. Feedback strategy and achievement motivation, each having partial influence on the learning outcomes of understanding and application of the concept. The effect is more pronounced on the results of learning scores only (sig $<0.05)$. This is in line with previous average difference test results.

The findings of this research are in line with the results of Sunariyah (2016) study on the influence of learning strategies and achievement motivation on the students' learning outcomes and scientific attitudes with the findings that learning strategies and achievement motivation levels show that no interaction simultaneously influences students' learning outcomes and students' scientific attitudes. Similarly, this finding is in line with the results of Dimyati (2012) study on the influence of learning strategy and achievement motivation on the students 'learning outcomes and attitudes with the findings, that there is no interaction effect between learning strategy with achievement motivation toward learning outcomes and students' attitudes toward the subjects.

The analysis of whether or not there is an interaction between feedback strategy and achievement motivation can be explained based on the findings of Deci, Koester, Ryan (1999) research shows that when the teacher rewards concrete form as a feedback, intrinsic motivation is significantly reduced and students are reluctant to motivate or self-organize. Feedback as extrinsic rewards often encourages students to put more emphasis on incentives, leading to higher intensity of evaluation and competition rather than high involvement in learning. The theory that feedbacks serve as motivators or incentives for learning still holds true in today's classes, but it appears confusing to distinguish between praise and feedback related to learning content (Hattie, Timperley, 2007).

Therefore, Narciss and Huth (2004) suggest that the adjustment of content, function and format of feedback presentation should be based on consideration of the learning objectives and characteristics of the students to maximize the informative value of the feedback. The use of feedback strategies also depends heavily on how students process and interpret the information provided. To draw conclusions about the effects of various feedback strategies, it should be controlled not only on motivational and metacognitive factors but also on how individuals process feedback from teachers.

\section{Conclusion and Recommendations}

The results reveal three findings, namely: (1) there are differences in posttest score of understanding and application of concepts between groups of direct and indirect feedback strategies; (2) there is difference of posttest score of understanding and application of concept between high and low achievement motivation group: (3) interaction between feedback strategy with achievement motivation does not influence simultaneously to understanding and application of concept.

The recommendations of this study for National ideology and Citizenship Learning and future research are the following. It is advisable to use specific feedback designs in the lesson to optimize the achievements of learning outcomes especially those related to the ability of understanding and application of concepts. Specific feedback can help students to reduce the difference between the learning outcomes of understanding and the application of concepts achieved with teacher-or school-target outcomes or objectives.

In designing feedback on task response or learning evaluation, an important factor to note is that feedback should be oriented to answer three questions posed by teachers and / or students: (1) what are the objectives (what are the targets to be achieved?) (2) how my progress (what progress has been achieved to get to the goal? and (3) then what is the next goal (what activities need to be done to create better progress?) Teacher feedback design in addition to 
answering the three questions, another factor (2) the process of understanding tasks, (3) the dimensions of the metacognitive process and / or (4) the self-dimensional (unrelated to the task) dimensions.) Feedback has the same effects different on those dimensions.

An effective feedback design provides two types of information to students: verification and elaboration. Verification is defined as a simple assessment of whether an answer is true or not, and elaboration is the informational aspect of the message, and provides relevant guidance to guide students to get the correct answer. An effective feedback design contains verification and elaboration information.

Suggestions for future research on the area of feedback, are as follows: a) this research can be further developed by involving more and varied subjects and locations so that generalizations can be carried out on the results of the research; b) examines how feedback functions in other types of learning domains other than cognitive but also in the psychomotor and affective spheres; c) examines how feedback works in a learning environment with a constructivist paradigm as well as testing new feedback strategies in the environment; and d) linked to emerging technologies can be reviewed how effective technology-assisted feedback design for improved learning outcomes

\section{Acknowledgements}

Punaji Setyosari, Instructional Technologies, Universitas Negeri Malang, East Java, Indonesia, E-mail: punaji.setyosari.fip@um.ac.id

Haryono, Instructional Technologies, Universitas Negeri Malang, East Java, Indonesia, E-mail: haryono@um.ac.id

\section{References}

Anderson, L.W., Krathwohl, D.R. (2001). A Taxonomy for Learning, Teaching, and Assessing. New York: Logman.

Andrew.C. (2008). Correcting a Metacognitive Error: Feedback Increases Retention of Low Confidence Correct Responses. Journal of Experimental Psychology, 34 (4), 918-928. Retrieved from: https://www.google.co.id/?gws

Arends, R.L. (2008). Learning To teach. Seventh Edition. New York: McGraw Hill Companis.Inc.

Atmadi, A., \& Setyaningsih, Y. (2004). Educational Transformation Entering the Third Millennium. Yogyakarta: Kanisius Publisher Sanata Dharma University.

Birgit Harks. (2014). The effects of feedback on achievement, interest and self-evaluation: the role of feedback's perceived usefulness. Educational Psychology, 34 (3), 269-290. Retrieved from: https://www.google.co.id/?gws

Butler, R. (1987). Effects of different feedback conditions on motivational perceptions, interests, and performance. Journal of Educational Psychology, 79 (4), 474-482. Retrieved from: https://www.google.co.id/?gws

Butler, Andrew C, et al. (2007). The Multiple-Choice Tests, Journal of Experimental Psychology, 13 (4), $273-281$. Retrieved from: https://www.google.co.id/?gws

Brookart, Susan, M. (2006). How to give effective feedback to your students. Alexandra Virginia USA: Association for supervision and Curriculum Development (ASCD).

Christine, Harris. (2003). Social Decission Making Skills, Probe Research.

Retrieved from: https://www.google.com/search?q=Christine

David, D. Vaus. (2002). Analyzing Social Science Data: 50 Key Problems in Data Analysis, Thousand Oaks: Sage Publications, 31 (9).

Degeng, Nyoman, S. (2013). Learning Sciences. Bandung: Kalam Hidup

Gagne, R.M. (1985). The Conditions of Learning. Fourth edition. New York: CBS College Publishing.

Gopal Patil, S.S. (2015). Effectifeness of Juriprudential Inquiry Model of Teachhing on The Academic Achievement of Social Science Among secondary. School Student. International Multideciplinary Research Journal, 4, (12) .1-5. Retrieved from: https: //www.google.com//gws

Huda, M. (2014). Teaching and Learning Models. Yogyakarta: Student Literature. 
Joyce. B \& Weil. M. (2003). Models of Teaching. Fith Edition.New Delhi: Prentice-Hall of India.

Hatie, J. \& Helen Timperley. (2007). The Power of Feedback. Review of Educational Research, 77, (1), 81-112. Retrieved from: https://www.google.com/education

Haiti, J. \& Mark Gan. (2011). Intruction Based on Feedback, Hanbook Research on Learning and Instrauction, Chapter $13,249-270$.

Hailikari, Telle. (2009). Assessing University Students' Prior Knowledge Implications for Theory and Practice. University of Helsinki Deparement of Education. Research Report 227, (6). Retrieved from: https://helda.helsinki.fi/bitstream

James J. Burkitt. (2013). The Impact of Prior Knowledge about Visual Feedback on Motor Performance and Learning. Advancesin Physical Education, 3, (1), 1-9. Retrieved from: http://www.scirp.org/journal/

Jared A chase, Ramona Houmanfaas. (2009). The Differential Effects of Elaborative Feedback and Basic Feedback on Student Performance in a Modified, Perzonalized System of Instruction Course. Journal of Behavior Education, 18, 245-265. Retrieved from: www.unr.edu/psych/behavior

Jiirgen Wilbert, Michael Grosche, Heike Gerdes. (2015). Effects of Evaluative Feedback on Rate of Leraning and Taks Motivation: An Analogue Experiment. A Comtemporary Journal, 8, (2) .43-52. Retrieved from: www.ldworldwide.org/pdf/LDCJ

Kulik, J. A., \& Kulik, C. C. (1988). Timing of feedback and verbal learning. Review of Educational Research, 58, (1), 79-97. Retrieved from: www.epsteineducation.com/home

Marguerite G. Lodico., Dean T., Spaulding, Katherine H. Voegtle. (2006). Methods in Educational Research: From Theory to Practice. San Francisco: John Wiley \& Sons, .211.

Marieke Thurlings, at.all. (2013). Understanding feedback: A learning theory perspective. Journal homepage: Computers \& Education 9, 1-15. Retrieved from: www.sciencedirect.com/science

Eggen, P. \& Kauchak, D. (2012). Strategies and Models for Teachers: Teaching Content and Thinking Skills. Six Edition. Boston: Pearson Education.Inc.

Erwin, M. (2011). Education Citizenship of the Republic of Indonesia. Bandung: PT. Refika Aditama.

Marzano, R.J, Pickering, D.J \& Pollock, J.E. (2004) .Classroom Instruction that Works: Reseacrh-Based Strategies For Increasing Student Achievement. Chapter 8, 92.

Moreno, R. (2004). Effects of explanatory versus corrective feedback in discovery-based multimedia. Instructional Science, 32, 99-113. Retrieved from: https://books.google.com/books

Mory, E. Holland. (2011). Feedback Research Rivisited. Handbook of Research for Educational Communication and Technology, AECT, 29, 919-956. Retrieved from: www.aect.org/edtech/ed1

Narciss, Susanne. (2010). Feedback Strategies for Interactive Learning Tasks. Handbook of Research for Educational Communication and Technology, Chapter 11.126-140. Retrieved from: www.aect.org/edtech/ed1

Nwafor, C. E. (2014). Use of Jurisprudential Innovative Approach in teaching Basic Science: An alternative to Lecture Methode. International researchers, 3, (1), 62-67. Retrieved from: http://iresearcher.org/Current

Paul, C. Burnett. (2010). Praise and Feedback in Primary Classroom: Teachers 'and Student' Perspektives. Australian Journal of Educational, 10, 145-154. Retrieved from: https://www.google.co.id/?gws

Santoso, S. (2014). Parametric Statistics: SPSS concepts and applications. Jakarta: PT. Elex Media Komputindo.

Setyosari, P. (2013). Education and Development research strategy. Jakarta: Kencana Prenadamedia Group.

Sichinga, K.T. (2014). Factors Influencing Quality of Feedback in Teaching in Botswana Senior Secondary Schools. International Journal of Research in Social Sciences, 4, (1), 26-37. Retrieved from: www.ijsk.org/uploads/3/1/1/7/3117743/3

Perry Roy Hilton and Charlotte Brownlow. (2004). SPSS Explained, East Sussex: Routledge, 364. 
Sugiyono, (2014). Statistics for Research. Bandung: Alfabeta.

Shute, Valerie. J. (2008). Focus on Formative Feedback. Review of Educational Research, 78, (1), 153-159. Retrieved from: https://www.ets.org/Media/Research

Travers, J. R., \& Light, R. J. (1982). Learning from experience: Evaluating early childhood demonstration programs. Washington, oc: National Academy Press.

Veer Pal, Singh. (2010). Effectiveness of Jurisprudential Inquiry Model of Teaching on Value Inclination of School Students, Journal of Educational Research, 47 (2), 45-71. Retrieved from: https://www.google.com/search

Voerman, L. at.al. (2012). Types and frequencies of feedback interventions in classroom interaction in secondary education. Journal hompage: Teaching an Teacher education, 30.1-9. Retrieved from: https://www.google.com/search 